\title{
Designing a Model of Acceptance New Media Technologies (Media Convergence Emphasis )
}

\author{
Babak Rahnavard, Islamic Azad University, Iran. \\ Kamran Mohamad Khani, Islamic Azad University, Iran. \\ Aliakbr Farhanghi, Islamic Azad University, Iran \\ Amir Hossein Mohammad Davoudi, Islamic Azad University, Iran.
}

\begin{abstract}
:
This research methodology is applied research(descriptive) and data collection methods implemented with mix method (qualitative and quantitative),at first stage, researcher reviewed a literature in media technology transfer to identification effective components and indicators, at qualitative part of the research, Selected 10 media industry experts to interviewed for identify effective indicators, in quantitative research part, researcher made questionnaire was distributed in the statistical sample of 300 responder from the population of the study and 285 questionnaires were returned. After analyzing, questionnaire responses with Spss software, Cronbach's alpha coefficient (reliability) was obtained $\alpha=0.881$ and finally using structural equation modeling (SEM), to designing a model of acceptance new media technologies, evaluation of the model show an absolute fit index (root mean square error 0.094 and chi-square 0.00), Incremental Fitness index of 0.886 and Frugal Fitness index 3.48 , which indicates the acceptability.
\end{abstract}

Keywords: Media Convergence, New Media, Technology Transfer, Diffusion of innovation, Media strategy 


\section{Introduction}

Technological advances and convergence of technologies in the transformation of the media are important components. These structural changes occurred under the influence of digitization, a process that broke the boundary between electronic media services and caused the emergence of new forms of media (Babaei, 2013, p.101). In such conditions, when technology is imported, the rational default is the use of new technology and its acceptance. However, there are drivers and barriers for acceptance new technologies that will be effective in media strategic planning and finally resulted in the decision to use or not to use a new technology (Albarran, 2006, p.297). In recent years, numerous online media appeared that some of these were accepted by the audience and the rest were out of the competition (Khojasteh, 2013, p.5). In Iran, due to the development of information technology infrastructure, the high level of knowledge, access to the Internet and modern media have found very significant influence and have affected different aspects of people's lives. According to statistics on the Internet in the 2015 Middle East with penetration rate of $52.2 \%$, was significantly higher than the average Internet penetration rate in the world (46.4 percent) and Iran, with a penetration rate of $57.3 \%$ is higher than the average for the Middle East. This figure represents a penetration of Internet in Iranian users compared with other countries in the region.

\section{Theoretical Foundations and Research Literature}

\section{New Media}

Naturally, the impact of developments due to technology in new media is different and all of them will be affected the same way. As the severity of developments in some media is higher and authorities require to change their business model quickly and in short-term while provides more opportunities for developing new strategies for the media managers (Farhangi, 2009, p.28). These changes in technology have different effects on media industries. As some media industries such as music industry is most affected by the changes resulting from the emergence of new media (Eris and Buginese, 2005, p.61), and some media such as newspapers under tremendous pressure of changes resulting from the emergence of new media technologies that, in the figure below the effect of complexities of production process on the media business is visible (Olmsted et al, 2006, p.259). 


\section{Media Convergence}

Media convergence is media integration through digitization that the media industry, seek media convergence to produce and publish a variety of media content through tools and technological infrastructure in order to use a diverse audience and the impact of convergence process on content, audience, technology and media industries in recent years is evident (Roshandel, 2011, p.39). Jenkins suggest five processes about the media convergence including: the technological convergence (digitization), economic convergence, horizontal convergence of industries, social convergence of multi-task, the cultural convergence (content production by audiences) and Global Convergence (Global Village of McLuhan). Jenkins knows technological convergence as the result of transformation of words, images and sounds into digital information. In his view technological convergence facilitates the transfer of information between different media including print, radio, television and online (Jenkins, Duze, 2008). Economic convergence refers to horizontal integration of industries and the concept of ownership. So as it leads to reduced operating costs and ultimately increased income, for example, according to a frame Jenkins considered in outlining the dimensions of convergence Koladze explains its more details and argues that the media industry, follows media convergence to produce and publish a variety of media content through tools and technological infrastructure in order to use a diverse audiences (Klinenberg, 2005).

\section{Technology Acceptance Model (TAM)}

Technology Acceptance Model expressed by Davis et al in 2008, was formedbased on extensive research on the Technology Acceptance Model. They combine secondary technology acceptance theory and models of perceived ease of use and called it TAM (Alrafy, 2005, p.9).TAM is a complete model of the determinants of technology application. The results revealed that:

- Perceived of easy use and ability to present results, are the main predictors of perceived usefulness.

- Employment relationship is effective on the perceived usefulness.

- Computerized self-reliance and fear of computers are principal predictors of perceived ease of use.

- Perceived Usefulness is the strongest predictor of behavioral intention (Venkateshet al, 2008, p.273). 


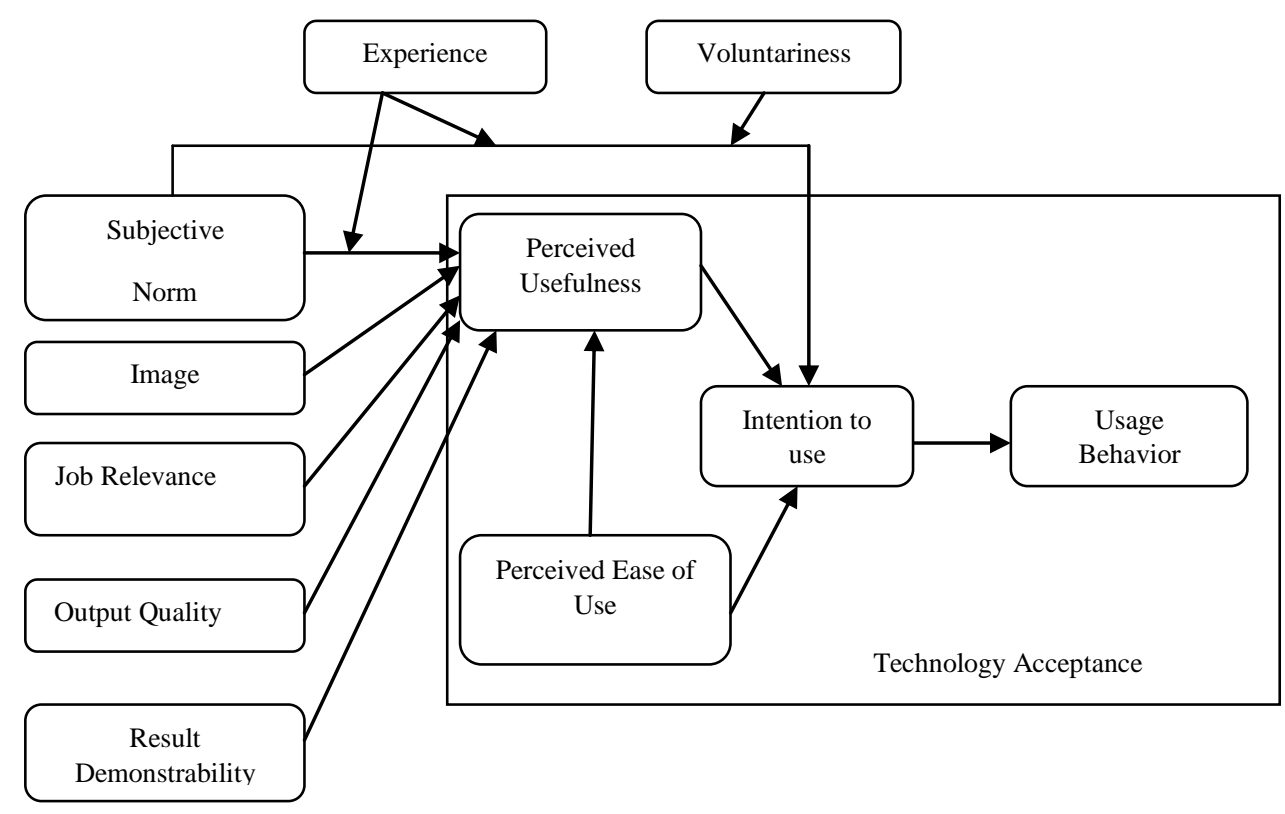

Figure (1): Technology Acceptance Model (TAM) (Venkateshet al, 2008, p.273).

\section{Unified Theory of Acceptance and Use of Technology (UTAUT)}

Unified theory of acceptance and use of UTAUT technology in 2003 was presented by Venkatesh and colleagues in order to develop the Technology Acceptance Model. The Technology Acceptance Model was proposed by Davis in 1985 based on the theory of reasoned action. This model specifically explained the behaviors of individuals in connection with the use of computer and different kinds of computer technologies (Chuttur, 2009, p.14).The basis of TAM consists of two specific ideas or beliefs that are the main factors associated with acceptance behaviors of computers: Perceived usefulness and perceived ease of use, that perceived usefulness is subjective probability formed in the users about the usefulness of a system dependent on technology, thus, it is more useful that the system improves their performance in their organizational context, and therefore will be used more. Perceived ease of use is subjective probability formed in the users about ease of use of a system which is dependent on technology, this means that, the system will be more used if it requires less effort to learn and use (Venkatesh et al., 2003, p.425). 


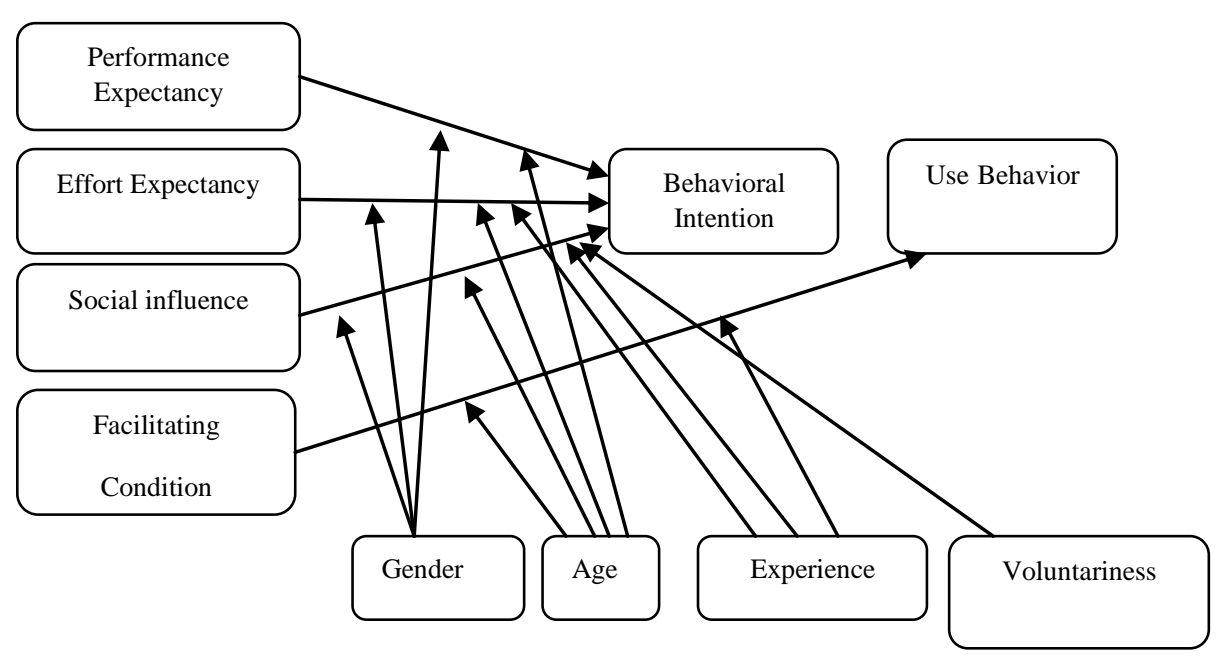

Figure (2): Unified theory of acceptance and use of technology (Venkatesh et al., 2003, p.425).

\section{Theory of Transfer and Diffusion of Technology}

In order to accept the technology, users must be participated in the acceptance process so that they will have mental readiness. So after the preparation and acceptance of technology the transfer process is done in order to institutionalize the technology in the society (Saryazdi, 2011, p.2). Users will be encouraged to use new technologies with the advent of them and new technologies will be alternative outdated technologies due to high performance, improved operations, easy accessibility and lower cost and users will strengthen their mental skills and abilities for business, localization and use of innovative technologies.

\section{Rogers' Innovation Diffusion Model}

The diffusion of innovation is a theory that deals with how and why a new idea diffuses in organizations, social networks and culture of the society. This diffusion is a process that an innovation will be diffused over time and with use of specified channels among members of a social system.In this theory, acceptance of innovation is presented as a process of collecting information and reducing uncertainty with regard to the evaluation of the technology. An individual's decision to use technology is based on individual's perceptions of technology such as comparative advantage, compatibility, complexity, testability and observability (Chen et al., 2006).Rogers has classified selectors of innovations based on the acceptance that they give to innovation, into several groups of innovators, early acceptors, early majority, the secondary majority and skeptics (Ghazi Nouri et al., 2012, p.73). 


\section{Senior Technology Acceptance \& Adoption Model}

STAM consists of the senior technology acceptance model and technology adoption model that progresses with a multi-faceted module of the primary ownership toward the actual acceptance.In this model, the technology recovery and acceptance factor among elderly users of mobile devices is presented and includes four phases of allocation (ownership), visibility (objectivity), joining (participation) and adoption and non-adoption (Renaud \& Biljon, 2008, p.5).

\section{Research Methodology}

Strategically, this research mix method, will be done using chain (sequential) method and the study population includes all experts of communications and media including professors and $\mathrm{PhD}$ students of communication and media management and experts working in the media industry, including managers of public affairs, the press and the media and media outlets, 10 people were also selected in the qualitative part for the interview and data collection and 300 people were selected in quantitative sampling, using purposive (non-random) sampling method to complete the questionnaire.

\section{Questions or Hypotheses}

\section{The main question:}

How is the model of acceptance and transfer of new technologies with media convergence approach, from the perspective of Iranian audience?

\section{Questions:}

1. What are the factors affecting the acceptance and transfer of new technologies by Iranian media audiences with media convergence approach?

2. How do these factors affect acceptance and transfer of new technologies by Iranian media audiences with media convergence approach?

3. What is an appropriate model for acceptance and transfer of new technologies by Iranian media audiences with media convergence approach?

4. What is the degree of appropriateness from the experts' perspective?

\section{Data Analyze and Research Findings}

The use of appropriate and accurate statistical methods can help the researcher in describing collected data and converting it to the information that they need.In this part of the research, 
the theoretical foundation, literature and information society model of some developing countries, whose condition was according to Iran, were evaluated and factors affecting these studies were extracted and indicators were completed using the history of previous researches.In the development of indicators affecting the acceptance and transfer of technology media, because of the overlapping, some indicators were combined for preserving independence of data and indicators that were not proportional with technology acceptance at the individual level were excluded from theindicators, then, based on the items of semistructured interview form, ten of the media industry experts were interviewed.At the end a number of indicators were identified based on the view of the interviewees and the final questionnaire was designed.In order to develop the quantitative part of the study and answer questions, the questionnaire was distributed among 300 identified statistical samples and collected questionnaires (285) were structured through factor analysis of equations and, an appropriate model for acceptance and transfer of new technologies by Iranian audiences with media convergence approach was extracted.

The first question: What are the factors affecting the acceptance and transfer of new technologies by Iranian media audiences with media convergence approach?

The questionnaire was designed based on the indicators identified in the theoretical foundation, literature and the results of interviews with media industry experts, that was given to predicted sample for doing the quantitative part of the study and answering the questions.

Table (1): Indicators of acceptance and transfer of media technology

\begin{tabular}{|c|c|c|c|c|}
\hline Variable & Index & ID & Item & Reference \\
\hline \multirow{10}{*}{ 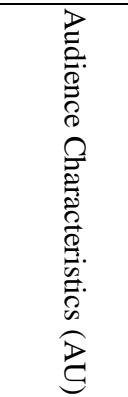 } & Age & A1 & Item1 & Venkatesh et al (2003) \\
\hline & Gender & $\mathrm{A} 2$ & Item2 & Venkatesh et al (2003) \\
\hline & Education & A3 & Item3 & Venkatesh et al (2003) \\
\hline & Job & A4 & Item4 & Venkatesh et al (2003) \\
\hline & Income & A5 & Item5 & Self-Administered \\
\hline & Audience Identity & A6 & Item6 & Eskandrei ( 2013) \\
\hline & Privacy & A7 & Item7 & Self-Administered \\
\hline & Subjective Norm & A8 & Item8 & Austermann (2014) \\
\hline & Trust and loyalty & A9 & Item9 & Rauniar (2014) \\
\hline & Innovativeness & A10 & Item10 & Self-Administered \\
\hline \multirow{7}{*}{ 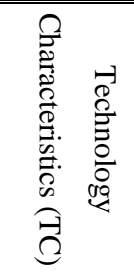 } & PConvergence of Media Channels & T1 & Item11 & Langer et al (2013) \\
\hline & Hardware and Software Facilities & $\mathrm{T} 2$ & Item12 & Khaniakil (2013) \\
\hline & Diversity of Media Technology & T3 & Item13 & Jenkins et al (2006) \\
\hline & Newness and Up to Date Technology & T4 & Item14 & Self-Administered \\
\hline & Data Transfer Rate & T5 & Item15 & Self-Administered \\
\hline & Fun \& Enjoyment & T6 & Item16 & Nirov (2011) \\
\hline & Display Quality / Resolution & $\mathrm{T} 7$ & Item17 & Venkatesh et al (2008) \\
\hline
\end{tabular}


Online Journal of Communication and Media Technologies Volume: 7 - Issue: 4 October - 2017

\begin{tabular}{|c|c|c|c|c|c|}
\hline & Comparative Advantage of Technology & $\mathrm{T} 8$ & Item18 & Jiyoung Cha (2013) \\
\hline & & Expected Performance & T9 & Item19 & Venkatesh et al (2014) \\
\hline & & Compatibility & $\mathrm{T} 10$ & Item20 & Jiyoung Cha (2013) \\
\hline \multirow{10}{*}{\multicolumn{2}{|c|}{ 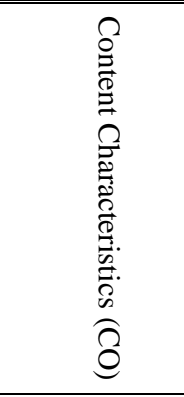 }} & Content Time & $\mathrm{C} 1$ & Item21 & Ma et al (2008) \\
\hline & & Richness of Content & $\mathrm{C} 2$ & Item22 & Bettiga et al (2013) \\
\hline & & Multimedia & $\mathrm{C} 3$ & Item23 & Petrovich (2009) \\
\hline & & Multiple Access & $\mathrm{C} 4$ & Item24 & Self-Administered \\
\hline & & Content Sharing & $\mathrm{C} 5$ & Item 25 & Dailey et al (2003) \\
\hline & & User-created Content & C6 & Item26 & Farhanghi (2009) \\
\hline & & General Content & $\mathrm{C7}$ & Item27 & Farhanghi 2009 \\
\hline & & Unique Content & $\mathrm{C} 8$ & Item 28 & Farhanghi 2009 \\
\hline & & Participation in Content Production & C9 & Item29 & Dailey et al 2003 \\
\hline & & Creative Content Production & $\mathrm{C} 10$ & Item30 & Self-Administered \\
\hline \multirow{5}{*}{\multicolumn{2}{|c|}{ 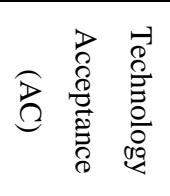 }} & Attitudinal Acceptance & AC1 & Item31 & Venkatesh et al 2000 \\
\hline & & Intentional Acceptance & AC2 & Item32 & Venkatesh et al 2008 \\
\hline & & Behavioral Acceptance & AC3 & Item33 & Venkatesh et al2008 \\
\hline & & Perceived Usefulness & AC4 & Item34 & Venkatesh et al2008 \\
\hline & & Perceived Ease of Use & AC5 & Item35 & Venkatesh et al2008 \\
\hline \multirow{7}{*}{ 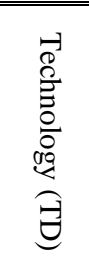 } & \multirow{7}{*}{ 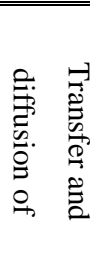 } & Social Impact of Technology & TT1 & Item36 & Renaud et al 2008 \\
\hline & & Access to the Infrastructure Costs & TT2 & Item37 & Zhang 2008 \\
\hline & & Cultural and Social Issues & TT3 & Item38 & Akbari et al 2013 \\
\hline & & National Policy and Communication & TT4 & Item39 & Hanson et al 1990 \\
\hline & & Technology Pressure & TT5 & Item40 & Self-Administered \\
\hline & & Censorship and Restrictions & TT6 & Item41 & Hanson et al 1990 \\
\hline & & Intend To Self-Fulfillment in Society & TT7 & Item42 & Self-Administered \\
\hline
\end{tabular}

Second question: How can these factors affect the acceptance and transfer of new technologies by Iranian media audiences with media convergence approach?

In order to answer the second question of the study about determining the effect of identification factors in the first question on acceptance and transfer of new technologies by Iranian audiences with media convergence approach,a questionnaire containing 42 items were distributed among the sample included 300 experts of communications and media including professors and $\mathrm{PhD}$ students of communication and media management and experts working in the media industry, including managers of public affairs, the press and the media and media outlets.After collecting, the questionnaires were analyzed and used in the inferential statistics to analyze the data and model designing by AMOS software. Also, in order to evaluate the effect of identified factors on the acceptance and transfer of new technologies by Iranian media audiences with media convergence approach, data collected by questionnaire was analyzed using confirmatory factor analysis and structural equation model. 


\section{Structural Evaluation of Audience Features:}

\section{One dimensional item:}

Being one dimensional is occurred when the items has an acceptable load factor (above 0.5) for the corresponding structure in which items with high load factor (above 0.5) are: audience age (A1), audience gender (A2), audience identification (A6), privacy statements of audience (A7), trust and loyalty of the audience (A9), that the media audience with the highest load factor in the audience structure (greater than 0.5) was identified and collected data after analysis by Amos software was validated.

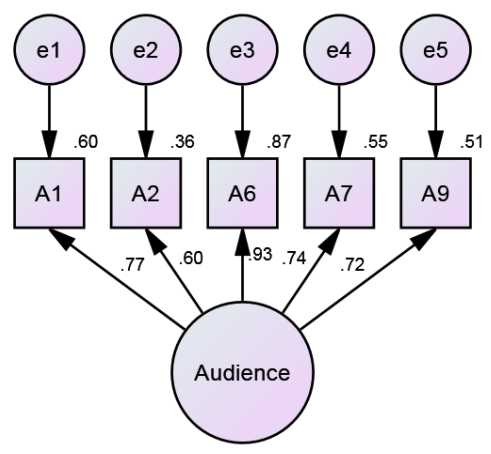

Figure (3): Structural evaluation model of media audience features

Convergent validity: In items of media audience structure the mean-variance is 0.61 , then the structure has convergent validity.

Structural Validity: absolute, incremental and frugal fitness

Value of root mean square error of the model is 0.1 and the probability of significance level is 0.001 , that the results are within acceptable limits, so we can conclude that the structure has an absolute fitness, furthermore, the comparative fitness index is 0.9 , which indicates that the structure has an increasing fitness and chi-square / degrees of freedom is 4.27, which confirms the frugal fitness in the structure.

Divergent validity: The correlation between each pair of eccentric structures is less than 0.85 , so the divergence validity of the evaluation model is confirmed.

Reliability: Cronbach's alpha coefficient was 0.86 based on the calculations conducted and the reliability of structure is confirmed.

\section{Structural Evaluation of Media Technology Features}

\section{One dimensional item:}

Being one dimensional is occurred when the items has an acceptable load factor (above 0.5) for the corresponding structure in which items with high load factor (above 0.5) are: 
convergence of media channels (T1), and newness and being updated (T4), data transfer rate (T5), display quality / resolution (T7) expected performance (T9), that the mediatechnology with the highest load factor in the audience structure (greater than 0.5) was identified and collected data after analysis by Amos software was validated.

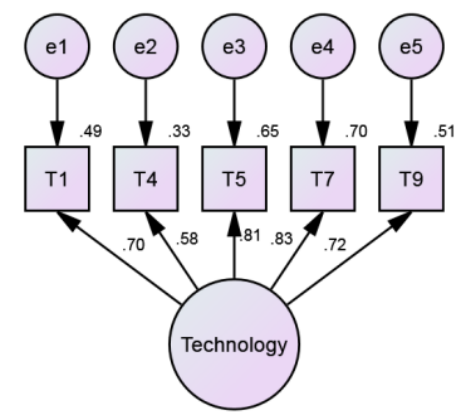

Figure (4): Structural evaluation model of media technology features

Convergent validity: In items of media audience structure the mean-variance is 0.56 , then the structure has convergent validity.

Structural Validity: absolute, incremental and frugal fitness:

Value of root mean square error of the model is 0.096 and the probability of significance level is 0.003 , that the results are within acceptable limits, so we can conclude that the structure has an absolute fitness, furthermore, the comparative fitness index is 0.9, which indicates that the structure has an increasing fitness and chi-square / degrees of freedom is 3.64, which confirms the frugal fitness in the structure.

Divergent validity: The correlation between each pair of eccentric structures is less than 0.85 , so the divergence validity of the evaluation model is confirmed.

Reliability: Cronbach's alpha coefficient was 0.84 based on the calculations conducted and the reliability of the structure is confirmed.

\section{Structural Evaluation of Media Content Features:}

\section{One dimensional item:}

Being one dimensional is occurred when the items has an acceptable load factor (above 0.5) for the corresponding structure in which items with high load factor (above 0.5) are: Content time (C1), multimedia (C3), content sharing (C5), general content (C7) and participation in content production (C9), that the media content with the highest load factor in the audience structure (greater than 0.5) was identified and collected data after analysis by Amos software was validated. 


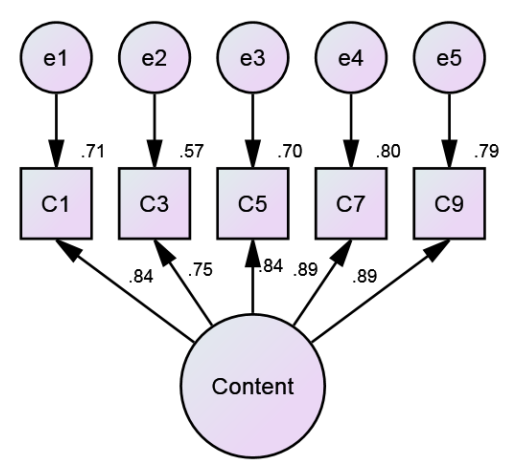

Figure (5): Structural evaluation model of media content features

Convergent validity: In items of media audience structure the mean-variance is 1.4 , then the structure has convergent validity. Structural Validity: absolute, incremental and frugal fitness: Value of root mean square error of the model is 0.088 and the probability of significance level is 0.007 , that the results are within acceptable limits, so we can conclude that the structure has an absolute fitness, furthermore, the comparative fitness index is 0.9 , which indicates that the structure has an increasing fitness and chi-square / degrees of freedom is 3.218, which confirms the frugal fitness in the structure.

Divergent validity: The correlation between each pair of eccentric structures is less than 0.85 , so the divergence validity of the evaluation model is confirmed.

Reliability: Cronbach's alpha coefficient was 0.925 based on the calculations conducted and the reliability of the structure is confirmed.

\section{Structural evaluation of media technology acceptance:}

\section{One dimensional item:}

Being one dimensional is occurred when the items has an acceptable load factor (above 0.5) for the corresponding structure in which items with high load factor (above 0.5) are: behavioral intention (AC2), real behavior (AC3), perceived ease of use (AC4) and perceived usefulness (AC5), that the media technology acceptance with the highest load factor in the audience structure (greater than 0.5) was identified and collected data after analysis by Amos software was validated. 


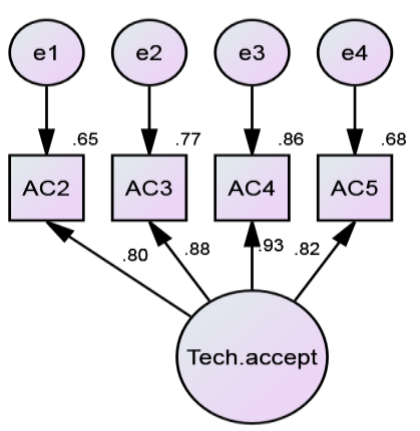

Figure (6): Structural evaluation model of media technology acceptance

Convergent validity: In items of media audience structure the mean-variance is 0.54 , then the structure has convergent validity.

Structural Validity: absolute, incremental and frugal fitness:

Value of root mean square error of the model is 0.088 and the probability of significance level is 0.022 , that the results are within acceptable limits, so we can conclude that the structure has an absolute fitness, furthermore, the comparative fitness index is 0.9, which indicates that the structure has an increasing fitness and chi-square / degrees of freedom is 3.8, which confirms the frugal fitness in the structure.

Divergent validity: The correlation between each pair of eccentric structures is less than 0.85 , so the divergence validity of the evaluation model is confirmed.

Reliability: Cronbach's alpha coefficient was 0.913 based on the calculations conducted and the reliability of the structure is confirmed.

\section{Structural Evaluation of Transfer and Diffusion of Media:}

\section{One dimensional item:}

Being one dimensional is occurred when the items has an acceptable load factor (above 0.5) for the corresponding structure in which items with high load factor (above 0.5) are: The social impact of technology (TT1), national policy of Communication and Technology (TT4), technology pressure (TT5), censorship and restrictions (TT6), tend to self-flourish in society (TT7), that transfer and diffusion of media with the highest load factor in the audience structure (greater than 0.5) was identified and collected data after analysis by Amos software was validated. 


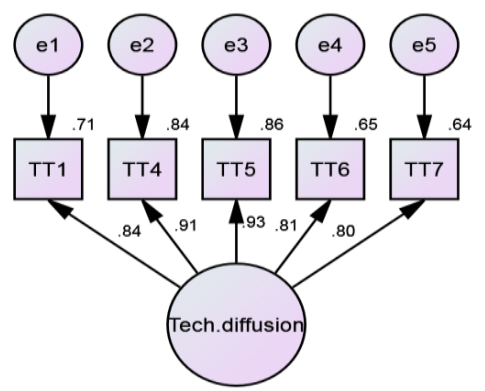

Figure (7): Structural evaluation model of transfer and diffusion of media

Convergent validity: In items of media audience structure the mean-variance is 1.2 , then the structure has convergent validity.

\section{Structural Validity: Absolute, Incremental and Frugal Fitness:}

Value of root mean square error of the model is 0.086 and the probability of significance level is 0.008 , that the results are within acceptable limits, so we can conclude that the structure has an absolute fitness, furthermore, the comparative fitness index is 0.9 , which indicates that the structure has an increasing fitness and chi-square / degrees of freedom is 3.11, which confirms the frugal fitness in the structure.

Divergent validity: The correlation between each pair of eccentric structures is less than 0.85 , so the divergence validity of the evaluation model is confirmed.

Reliability: Cronbach's alpha coefficient was 0.931 based on the calculations conducted and the reliability of the structure is confirmed.

\section{Data normality evaluation}

After evaluating the data fitness in the model, the normality of the data was assessed so that the structural model evaluation will be performed after normality of data.In the case that Skewness and kurtosis of the data is in the range of +2 and -2 , the data are normal, that the study shows that the normality of the data will be accomplished.

The third question: What is the appropriate model for accept and transfer the new media technologies by Iranian audience with media convergence approach?

In order to answer the third research question, the analysis of the structural model will be used in modeling. So that after confirming the one dimension, the validity and reliability of the model evaluation, modeling of the structures will be confirmed with items and structures have been arranged from left to right in terms of being effective.So that the output structure 
will be placed on the left, mediating structure in the middle and input structure on the right side of models.

Structural diagram of the model of acceptance and transfer of new media technologies

To design the model of acceptance and transfer of new media technologies by Iranian media audiences with media convergence approach on the basis of research literature, structures have been arranged and model fitness parameters were calculated that the model fitness is in accordance with the standards.

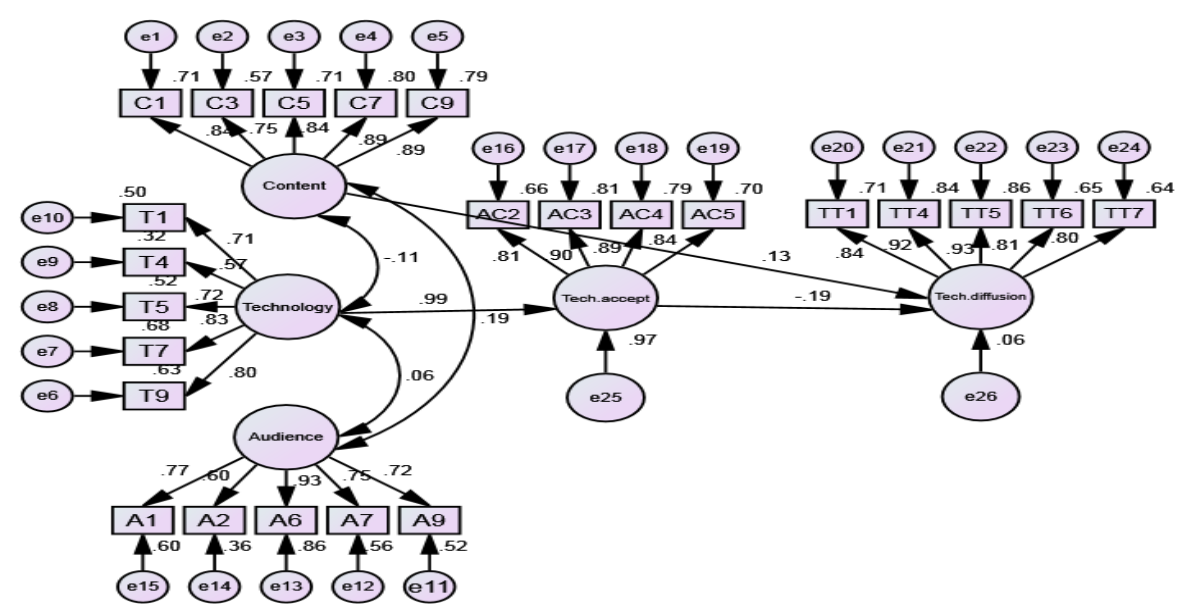

Figure (8): Structural diagram of the Media technology acceptance and transfer

By analyzing data extracted, it was found that absolute, incremental and frugal fitness is within the standard range. Therefore the structure diagram obtained by analysis of Amos software has fitness. Introduction of an appropriate model for acceptance and transfer of modern media technologies Fitted diagram with three output structure, an intermediate structure and an input structure was confirmed in terms of the structural model analysis that the figure (9) representing the final frame of fitted model.

Table (2): Fitness of the model of acceptance and transfer of media technology

\begin{tabular}{|c|c|c|c|c|}
\hline Fitting Indexes & Index Name & Standardized Estimates & Index & Result \\
\hline Absolute Fitness & RMSEA $^{1}$ & $0 / 05<$ RMSEA $<0 / 1$ & $0 / 094$ & Accept \\
\hline
\end{tabular}

\footnotetext{
${ }^{1}$ Root Mean Square Error of Approximation
} 


\begin{tabular}{|c|c|c|c|c|}
\hline & P- Chisq & $\mathrm{P}<0 / 05$ & $0 / 000$ & Accept \\
\hline Incremental Fitness & $\mathrm{CFI}^{2}$ & $0 / 7<\mathrm{CFI}<0 / 9$ & $0 / 886$ & Accept \\
\hline Frugal Fitness & $\mathrm{CHISQ}^{2} \mathrm{DF}^{3}$ & $5>\mathrm{CHISQ} / \mathrm{DF}$ & $3 / 48$ & Accept \\
\cline { 2 - 5 } & &
\end{tabular}

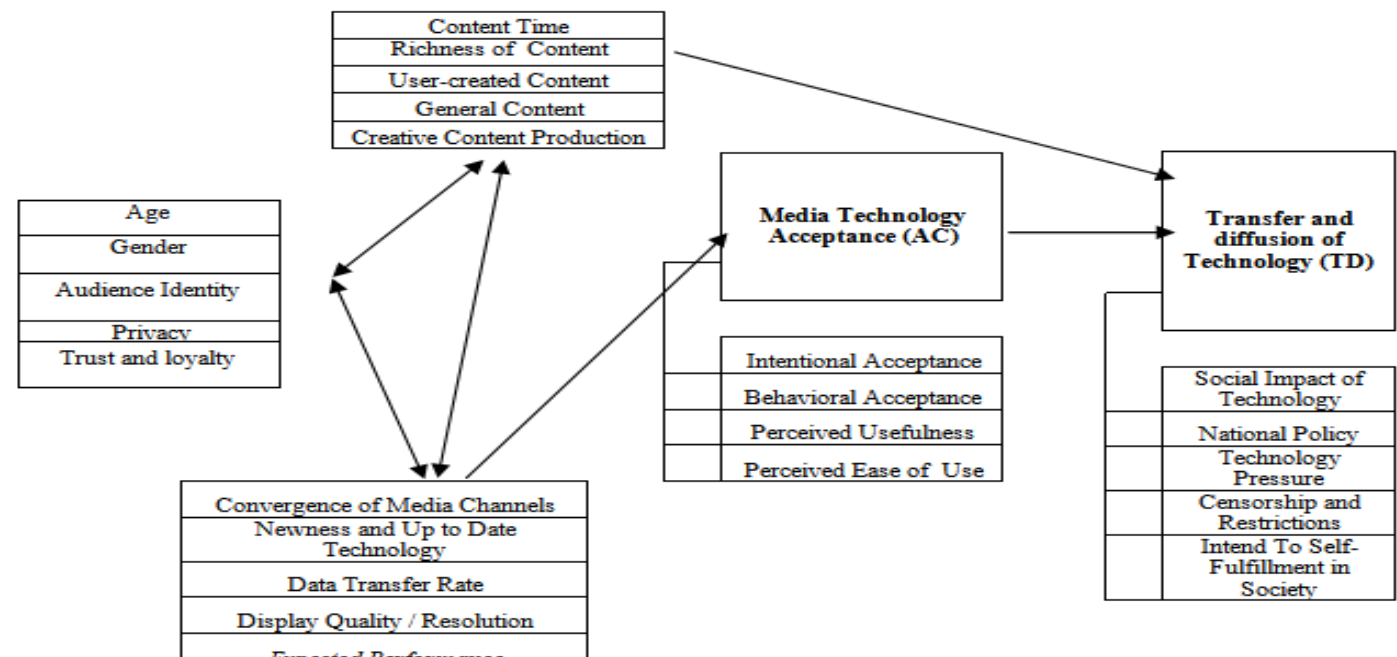

Figure (9): Appropriate model for acceptance and transfer of new media technologies

Fourth question: What is the degree of appropriateness of the proposed model from the experts' perspective?

In order to assess the appropriateness (fitness) of each of the structures and items that have been confirmed in the process of confirmatory factor analysis of the model structure, factor analysis modeling method is used and then using the Friedman ranking test,the outcome variables that had the most and least impact on the model were identified.Friedman test has been used in order to rank the factors related to the research dimensions that, the Spss output includes two table.In the second table, the mean rank for each variable has been presented and statistical characteristics and $\chi^{2}$ statistics have been presented in the first table. According to the Spss output, the significance value (sig) is less than the standard significance level $(\alpha=5 \%)$. Therefore we can say that there is a significant difference between output variables of acceptance and transfer of new media technology. As can be seen in the average rank table, the lowest rank is related to $\mathrm{C} 1$ (content time) with a mean of 3.64 , and the highest rank is related to A7 (privacy of the audience) with the mean of 10.54 .

\footnotetext{
${ }^{2}$ Comparative Fit Index

${ }^{3}$ Chi square/ degree of freedom
} 


\section{Discussion and Conclusions}

The rapid changes taking place in the media industry will be effective on various aspects such as media content, media audience, media technology (form and infrastructure), therefore, audiences will be faced with the challenge due to the use of traditional media, in the face of these increasing media changes that will have a major impact by them on the acceptance and transfer of emerging technologies. The acceptance of technology especially emerging media technologies is a converging and interaction-cognitive that several parameters affect them.With the emergence of new media as a result of the convergence, traditional media will be subject to continuous and forced changes and the audiences will have permanent and uninterrupted connection to the media and there will be no specific physical location to produce and broadcast programs, cyber and intelligence will be an inseparable part of all media. In this study, the subject of convergence, acceptance and transfer of media technology by Iranian audiences with a special focus on audience, media content and technology were analyzed that shows the results. There is a two-way interaction between the features of audiences of new media with the components of age, gender, audience identification, privacy, trust and loyalty of the audience, the characteristics of media content with the components of content time, content richness, user-created content, public content and creative content production and technical characteristics of new media with convergent components of media channels, and newness and updated technology, data transfer rate, display quality and performance expected.The characteristics of technology affected the acceptance of technology with components of behavioral intention, real behavior, perceived ease of use, perceived usefulness and finally, after the technology acceptance causes its transfer and diffusion at the society level.The content features affected the transfer and diffusion of media technology with components of social effect of the technology, national policy of communications and technology, technology pressure, content censorship and tendency to self-flourish in the society that, this model can be a good strategy for diffusing indigenous media technologies in accordance with the needs of Iranian audiences. 


\section{Reference}

Albarran,A; Chan-Olmsted,M, and Michael, O. (2006). Handbook of media Management and Economics, London, L.Erlbaum Association.

Alrafi, A. (2006). Technology Acceptance Model Retrieved 4th February 2009, from www.imresearch.org/RIPs/2005/RIP2005-4.pdf.

Ajzen,I.; Fishbein,M .(2002).Understanding attitudes and predicting social behavior. Prentice- hall, englewoodcliffs.

Aris, A.; Bughin, J. (2005). Managing Media Companies Managing Media Companies: Harnessing Creative Value, England, Wiley Publications.

Atkin,D.; Hunt,D, Carolyn, A. (2015). Diffusion Theory in the New Media Environment: Toward an Integrated Technology Adoption Model, Mass Communication and Society, 18(5), 623-650.

Babaei, M. (2012). Digital Media: participatory and technology-based, Monthly journal discourse of Science and Technology, 1(2), 5-22. (In Persian)

Brown, T. E.; Davidsson, P., \&Wiklund, J. (2001). An operationalization of Stevenson's nceptualization of entrepreneurship as opportunity-based firm behavior. Strategic Management Journal, 22(10), 953-968.

Chen, L., Gillenson, M. L., Sherrell, D. (2002). Enticing online consumers: An extended technology acceptance perspective. Information\& Management, 39(8), 705-719.

Chuttur, Mohammad. (2009). Overview of the Technology Acceptance Model: Origins, Developments and Future Directions, Indiana University, USA. Sprouts: Working Papers on Information Systems, 9(37).

Dailey, L.; Demo, L. Spillman, M. (2003). The convergence continuum: a model for studying collaboration between media newsrooms.

Farhanghi, A.; et al. (2009). Design interaction models and new technologies of information and communication Media Management, Journal of Communication researches, 16( 4),11-36.(In Persian)

Hanson, Jarice; Narula, Uma. (2011). New communication technologies in the developing countries. ( Heidari, Davod) Hillsdale, NJ, Lawrence Erlbaum.

Jenkins, H.; Deuze, M. (2008). Editorial: Convergence Culture. Convergence: The International Journal of Research into New Media Technologies, 14(1), 5-12.

Klinenberg, E. (2005). Convergence: News production in a digital age. Annals of the American Academy of Political and Social Science, 597(1), 48-64. 
Kolodzy, J. (2006). Convergence journalism: Writing and reporting across the news media. Lanham, MD: Rowman \& Littlefield Publishers, Inc.

Khojasteh, H.; et al. (2012). Models comply with media technology. The Quarterly Journal of Media Scientific, 24(3), 5-22. (In Persian)

Lin, C. (2003). An interactive communication technology adoption model. Journal Communication Theory, 13(4), 345-365.

Lin, C. (2009). Exploring the online radio adoption decision-making process: Cognition, attitude, and technological fluidity. Journalism \& Mass Communication Quarterly, 86(4), 884-899.

Napoli, P. (2008). Towards a model of audience evolution: New technology and the transformation of media audience. New York, Paperwork. The Donald McGannon Communication Research Centre.

Phillips, J. (2014). Examining Predictors of U.S. Student Intent to Study Abroad from a Communication Perspective. Open Access Dissertations, Paper 1346.

Rogers, E. (1995). Diffusion of Innovations (4th Edition). The Free Press, New York, USA. A Division of Simon \& Schuster Inc.

Renaud, Karen; Biljon, Judy. (2008). Predicting technology acceptance and adoption by the Eldry: a Qualitative study, SAICSIT 08, South Africa.

Roshandel, T.; et al. (2011). Effects of convergence on print news media management, case study Citizen Newspaper, Public Administration, 3(8), 39-56 .(In Persian)

Saryazdi, A.; et al. (2011). Analyzed the impact of technology on organizational behavior using system dynamics approach, 1th International Conference on Technology Management, Tehran, Iran.(In Persian)

Venkatesh, V.; Morris, M.G., Davis, F.D. and Davis, G.B. (2003), User Acceptance of Information Technology: Toward a Unified View, MIS Quarterly, 27(3), 425-478.

Zhang, Sheng. (2012), the convergence of conventional media and new technology, the case of the New York time broadcastion, p293. 